\title{
BEEN THERE, DONE THAT
}

\section{Antarctica}

\section{S Horne}

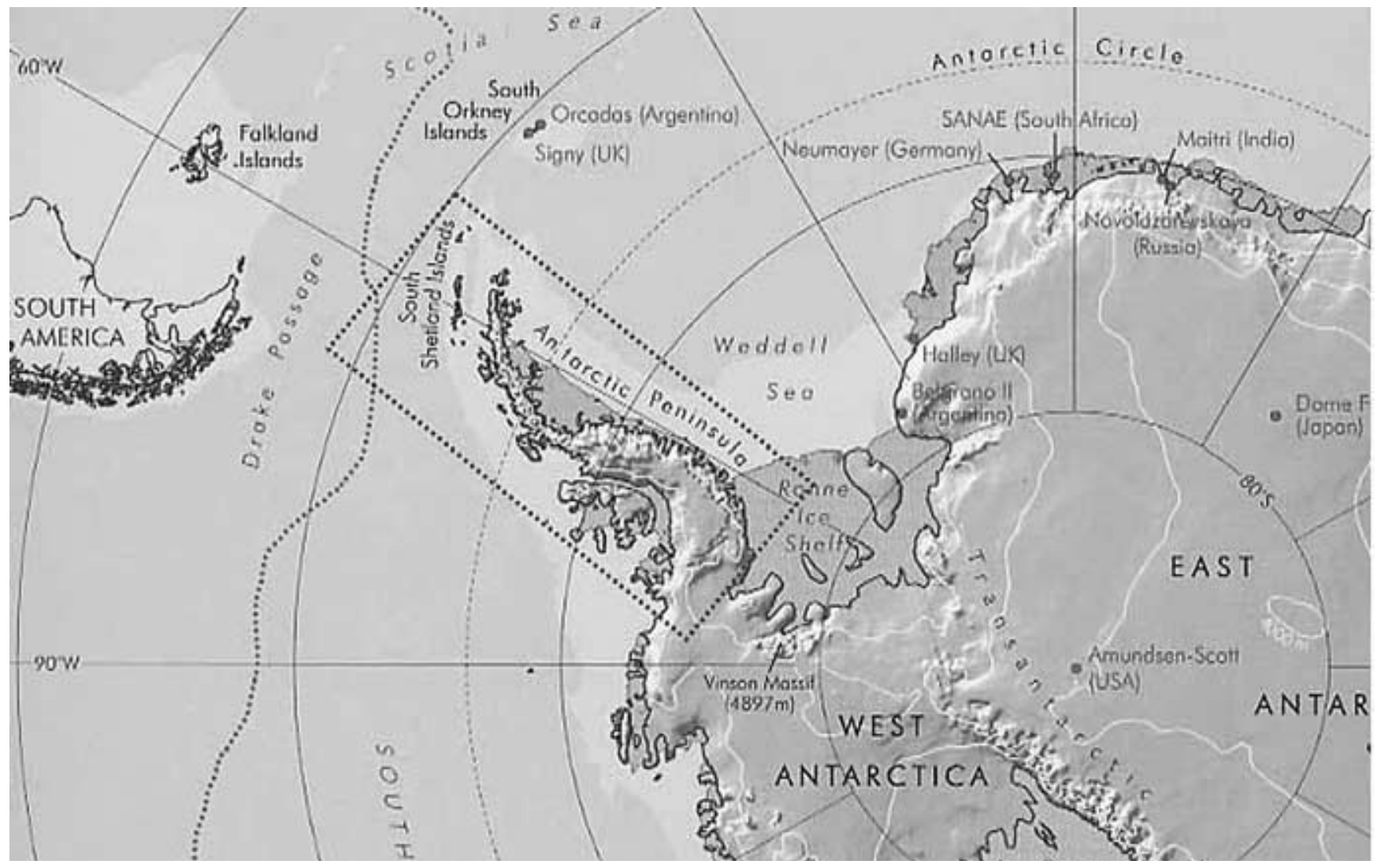

Fig 1. Map.

\section{Introduction}

In mid November 2001 I and fifteen other climbers and sailors, many of us novices, started our three month leg of the British Army Antarctic Expedition (BAAE). The whole expedition involved sailing a $72 \mathrm{ft}$ Yacht, the John Laing, from Portsmouth to Antarctica, there to explore by sail and ski, before sailing back to the UK. In all, about 120 service personnel were involved, as a different crew sailed each of the seven legs.

\section{Preparation}

Initial preparation for the expedition involved assessment of fitness of all involved, both for sea and land legs. Those solely involved in the sea legs needed to declare any illnesses which might recur during the crossing, and be generally fit enough to endure the rigours of the trip. The medical supplies for this leg were essentially those scaled for an ocean going vessel of the size of John Laing as laid down by the international guidelines. In addition there was an extended trauma care kit, and a larger range of IV equipment as the skipper was competent to use it if necessary.

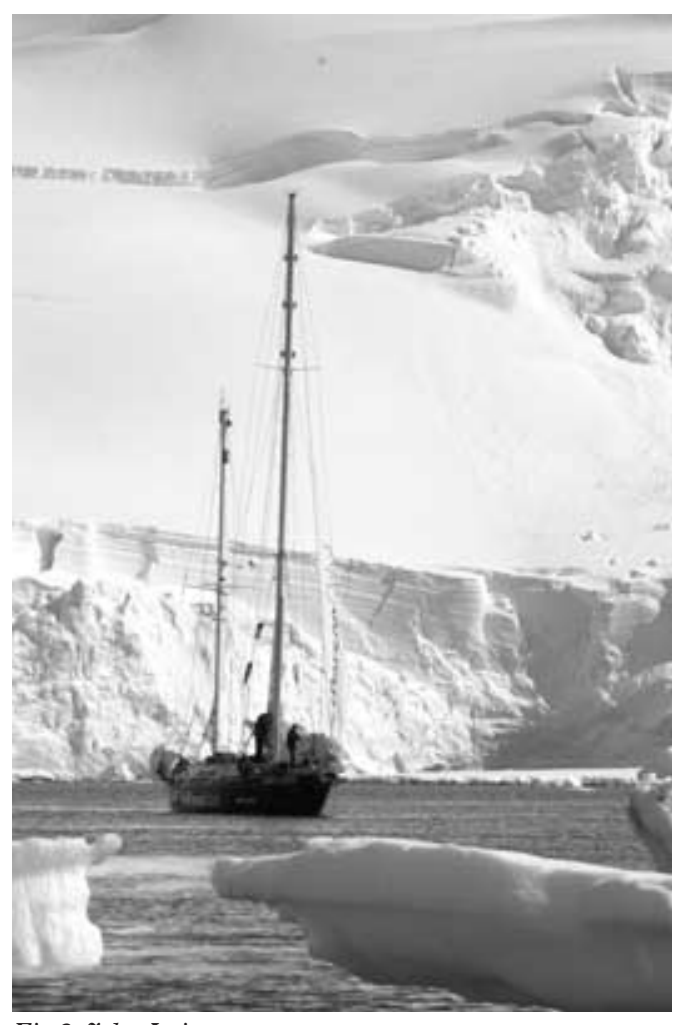

Fig 2. fohn Laing. 
Screening for the Antarctic phase required a higher level of fitness and injury screening, as well as screening for previous cold injury. The land phase offered more significant challenges in terms of medical support than the sea legs. For one, the risks of crevasse and avalanche were significant, as well as cold injury and simple trauma from skiing accidents (especially easy when dragging a heavy sled). In addition, I was not on the land team for large periods, and so they could be up to a week from medical help.

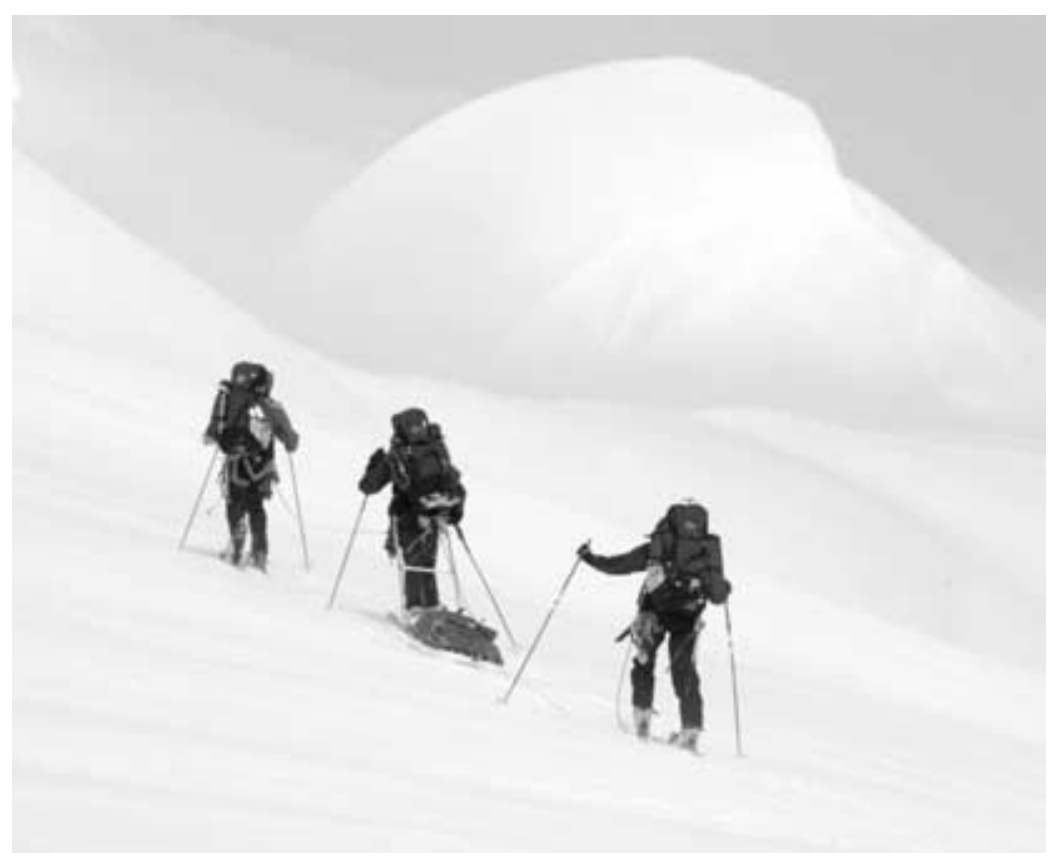

Fig 3. Man handling.

The "ropes" (of three climbers each) had a designated medic who had a greater understanding of the primary care treatments available from their medical packs, but everyone had to be able to step into that role in the event of an emergency. As a result there were numerous medical lectures and practical sessions for all team members, both pre-deployment and during the sailing phase. The medical packs themselves had to offer the widest treatment options possible, while still being light and compact (the mountaineers had already threatened to ditch their kit if they felt it was unduly heavy or bulky). In the end, it all fitted (just) into a one-litre Tupperware box, and none of the kits "fell" into any convenient crevasses.

\section{Sea Leg}

The Sea legs started some 3 months before I flew out to the Falklands, and involved crews from various regiments sailing out of sight of land for between 4 and 6 weeks each. The skipper had considerable experience having been a round the world competitor and having crossed the Atlantic several times. The bosun was also extremely capable, having spent his last 3 years living on the John Laing. There was not a circuit or piece of plumbing that he did not know well, and his knowledge was vital over the coming months as nearly 20,000 miles of hard sailing took its toll on crews and vessel alike. As an ocean sail training boat, leased from the Ocean Youth Trust, the John Laing was chosen for its durability (a steel hull was vital in the ice) and its inbuilt redundancy. If the engine failed we could sail. As a ketch, if we lost one mast, we could limp along with just the other. The rigging was entirely manual, with no self-furling devices, so that sails could easily be taken down and repaired if they tore. The only systems that were irreplaceable were the navigation computers, and even then the skipper started sextant and astronavigation lessons early on, so that should technology fail, we could fall back on the more traditional methods.

My sailing experience started on the 30th November 2001, after a week in the Falklands refitting the yacht for sea after her first eight thousand miles. The yacht was full to bursting with supplies. Of the twelve bunks for the "ordinary" crew all but six were full of mountaineering gear. An entire bunk was full of toilet paper - sixteen people use a lot over three months. Instead of climbing up to the lower bunk from the companionway, you climbed down as the floor had been raised three feet by boxes of tinned food, inflatable boats, and diesel.

Whilst I had some experience, dingy sailing off Torbay could not prepare me for what lay ahead of us. The first week introduced me to real ocean sailing, as we gently climbed and then plunged down waves the size of small hills, in heavy winds and rain. Land seemed like a distant memory, and we were utterly alone except for the tireless albatrosses and awesome whales, increasing in numbers as we crossed the convergence into Antarctic waters.

Sailing in the ocean is very physically demanding. The watch system allows plenty of sleep but in small sessions - two watches maintain a rolling rota of six hours on, six off in the day, and then three four hour watches over night. The Number One jib required at least three people to carry it up on to the foredeck, and when pitching and wet this was a dangerous place to be. All crew were required to wear lifejacket and harness at night, and whenever the weather roughened. Our oilskins were the top of the range, but while they usually kept the sea out they also kept the sweat in - one way or the other you were wet by the end of your watch. Nothing on board dried, and we had to sleep in bivi bags, as the breath condensing on the steel hull dripped down onto us as we slept. It was very exciting, but not a little miserable as well. I think everyone was grateful when we first saw the imposing peaks of Smith Island (the scene of previous Army expeditions) rising above the horizon, and we headed east towards our first landfall, the volcanic Deception Island. 


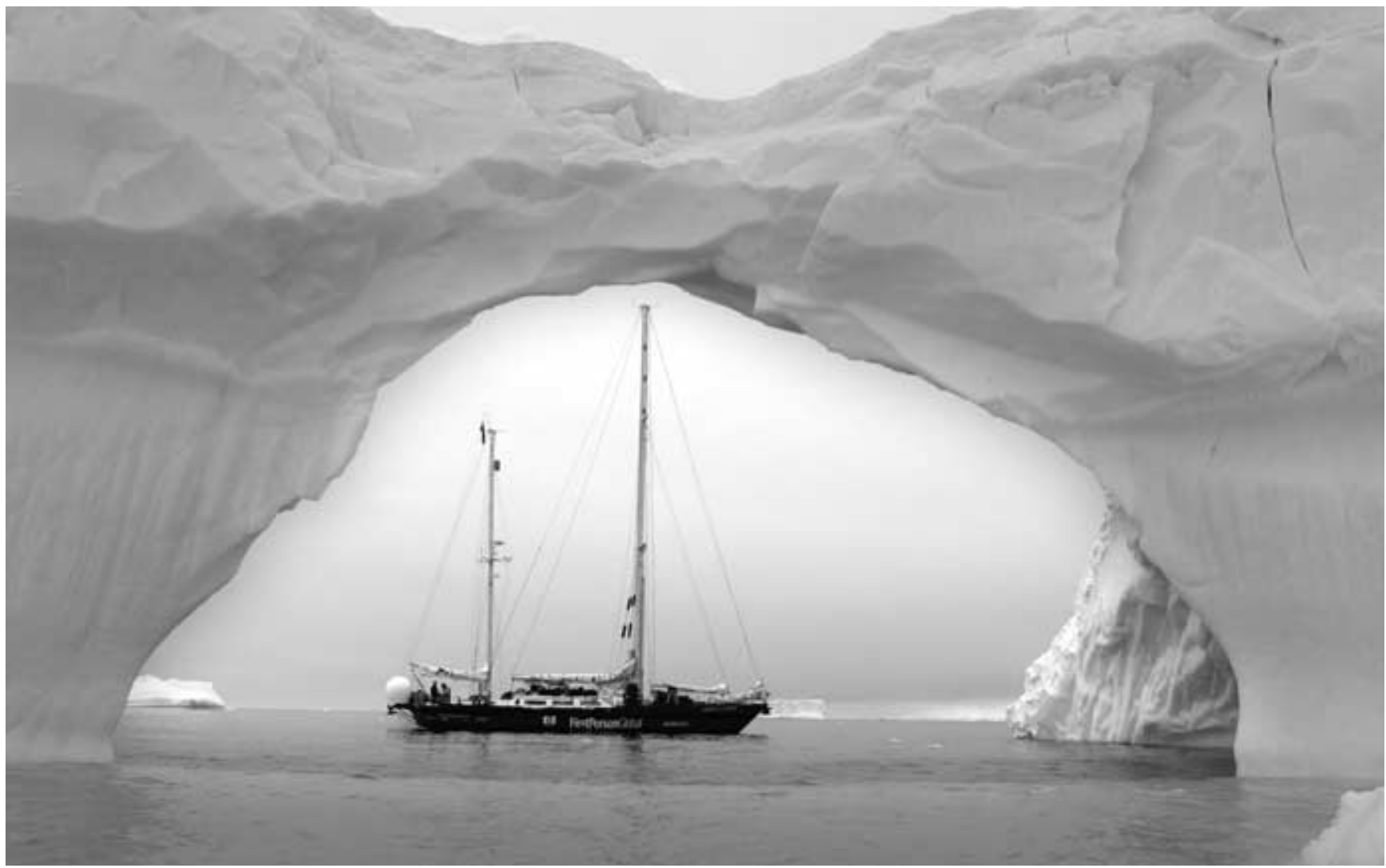

Fig 4. fohn Laing amid icebergs.

\section{Medical aspects of ocean sailing} Life aboard ship was in many ways just as dangerous as the climbing. On several occasions wind and ice conspired to tax the skills of our skipper to the absolute limit, and swinging booms and blocks of ice were a constant threat. On the first leg, from UK to the Canaries, one sailor fell hard and was later found to have fractured his neck of femur. This was undetected at the time as he continued to walk on it. The fracture was undisplaced and had not moved by his arrival in the canaries ten days later.

Sailing is a primary care nightmare. Everyone gets windburn, and chapped hands and lips. Neutrogena Norwegian formula helps reduce these problems, and a small tube lasts a long time. Seasickness is a horrible condition, fortunately usually only for the first few days. Stugeron (cinnarizine) was the prescription I was recommended, but the crew did not like it. Many described it as being like the general malaise they associated with taking Larium. Obviously as they were taking it prophylactically, this may have been a low level of seasickness getting through, but either way, many preferred just to be sick. They also complained that it gave them vivid disturbing dreams, but the skipper assures me that this is just a side effect of sailing itself. Although no one needed IM medication or parenteral fluids, dehydration took its toll early in the form of constipation and piles. The fact that the toilet was usually at a forty degree angle and that being below exacerbates seasickness probably worsened the situation. When the mountaineers got ashore and were living on dehydrated rations it became a real problem.

\section{The Land leg}

Our arrival at the Deception was the start of the main thrust of the expedition, as we then headed down the Gerlache Strait between mountainous islands and the imposing cliffs of the Antarctic Peninsula. Having identified a likely point for a man haul ascent up onto the peninsula, we landed nine climbers who then spent 15 days ascending to the plateau atop it, and then travelled to Mt Johnson and climbed it - only the second team ever to do so. I was not initially in the climbing teams, but as attrition reduced the numbers of climbers available I started to take a more active role, and in the end climbed four peaks, two of them first ascents. Having never climbed before, the experience of a twilight ice climb is one I shall never forget, and hope to repeat. Even when not climbing we were kept busy with a program of geological and biological data collection for various bodies, as well as heritage and hydrographic surveys.

Despite the ever-present danger of crevasses - such that stumbles into them by one member or other became a not infrequent occurrence, there were thankfully no major injuries. My nightmare appendicitis - struck after only three weeks, with a classical presentation in a young man. Our casevac options were limited at the time, and we ended up enlisting the aid of a Chilean re-supply vessel to take him north past Deception to the airstrip at Marsh, and 


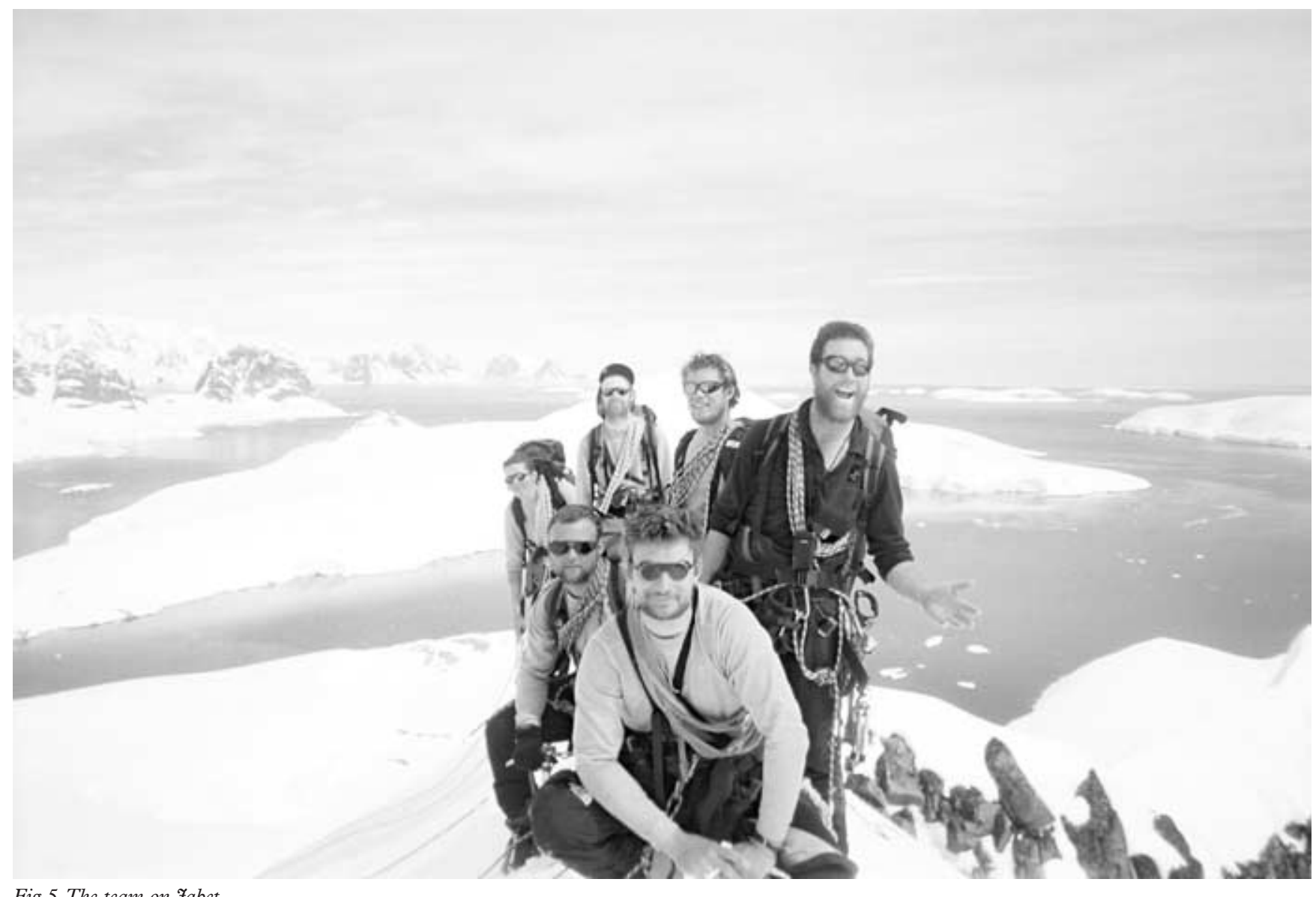

Fig 5. The team on fabet.

then on to Chile. In the event - after $48 \mathrm{hrs}$ of IV antibiotics - as we were approaching them, his fever broke and symptoms started to resolve. After consultation with Colonel Vassallo via the Telemedicine unit at Haslar, we decided to keep him on. Weeks later, he was in the team which reached the summit of Johnson.

One cold injury caused a little trouble. Predictably, it was in a man who had a previous injury from South Georgia (which he had kept quiet about), and who had not worn gloves. Despite refreezing at least twice before returning to the yacht it was superficial, and settled well with about $1 \mathrm{~cm}^{2}$ of skin being sloughed off. He was confined to day trips with adequate protection once all his symptoms had settled. They say education is the only way to prevent this, and it is true, but some are harder to teach than others. Even after the injury I had difficulty persuading this man to wear his gloves.

The injury that caused the most heartache was a fractured thumb (dominant) in a young officer when she fell $100 \mathrm{~m}$ down a steep sided peak. Uncertain whether it included significant injury to the joint, I was close to arranging casevac as we were in a relatively good location, rather than risk permanent disability. In the end (after trying 3 cruise ships whose machines were all broken) we managed to get an X-ray at Palmer Station (US). As a result I was able to take the decision to avoid evacuation and after I had manipulated it, the officer was able to continue to work on the yacht with her wrist in a cast. She has since been discharged from orthopaedic follow up with an excellent result.

My lessons were many, but here are a few of the most important:

\section{Preparation}

My kit was good, and I think would have managed in most foreseeable situations. A more robust screening system might have alerted me to the previous cold injury, and I would like to have had the time to train all of the climbers better. Redundancy is never wasted in terms of training - my RAMC medic had to pull out just before the trip started, and the patients with appendicitis and the fractured thumb were both the nominated medics for their ropes. Being a medic in the Antarctic is clearly a dangerous profession!

I was lucky in that I tapped into a wealth of experience from doctors who had spent time there before, and not one contact failed to produce vital gems which saved time and trouble later.

\section{$X$ - Rays}

The whole expedition was nearly ended early for one climber by a relatively small injury, as I was not able to "see" what she'd done. Space on the yacht was at a premium, but I later found out that the EOD X-ray device was originally designed to a medical specification. It is the size and weight of a bottle of champagne, with a developer set the 


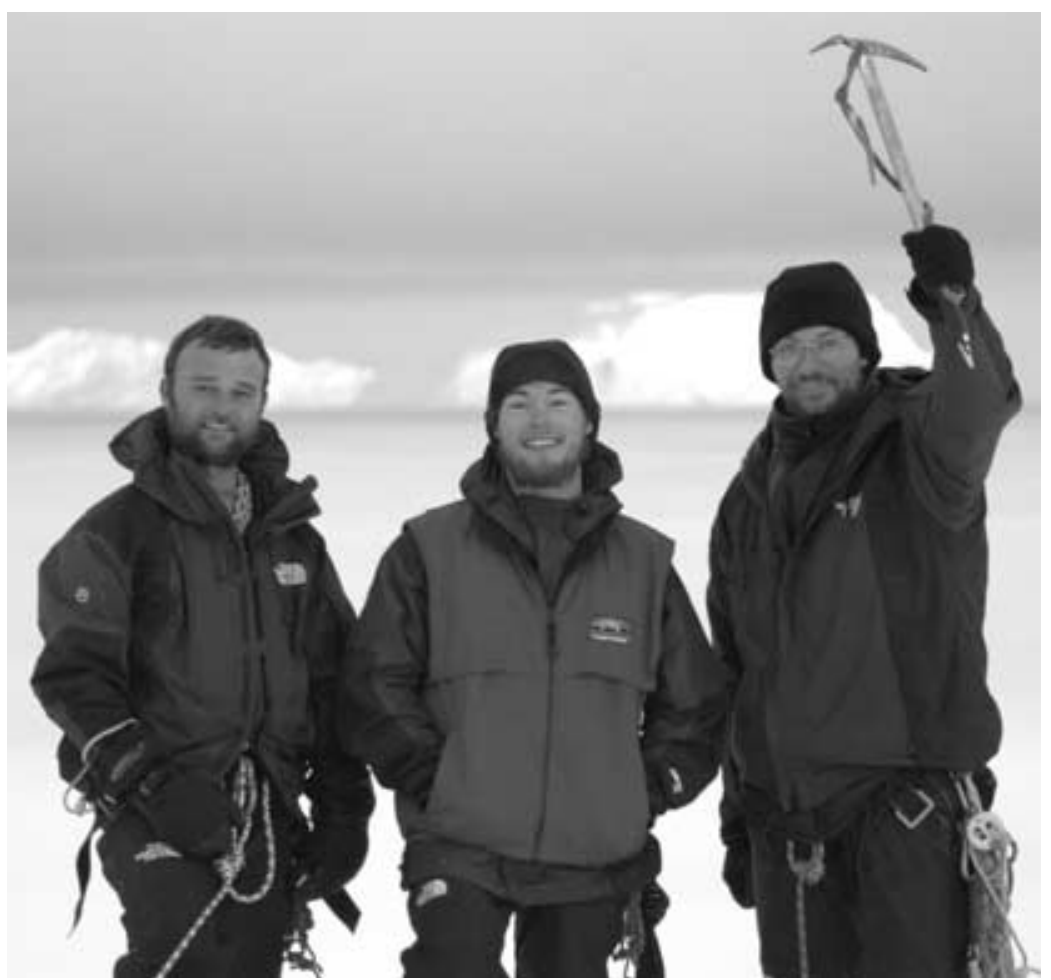

Fig 6. On top of pendragon.

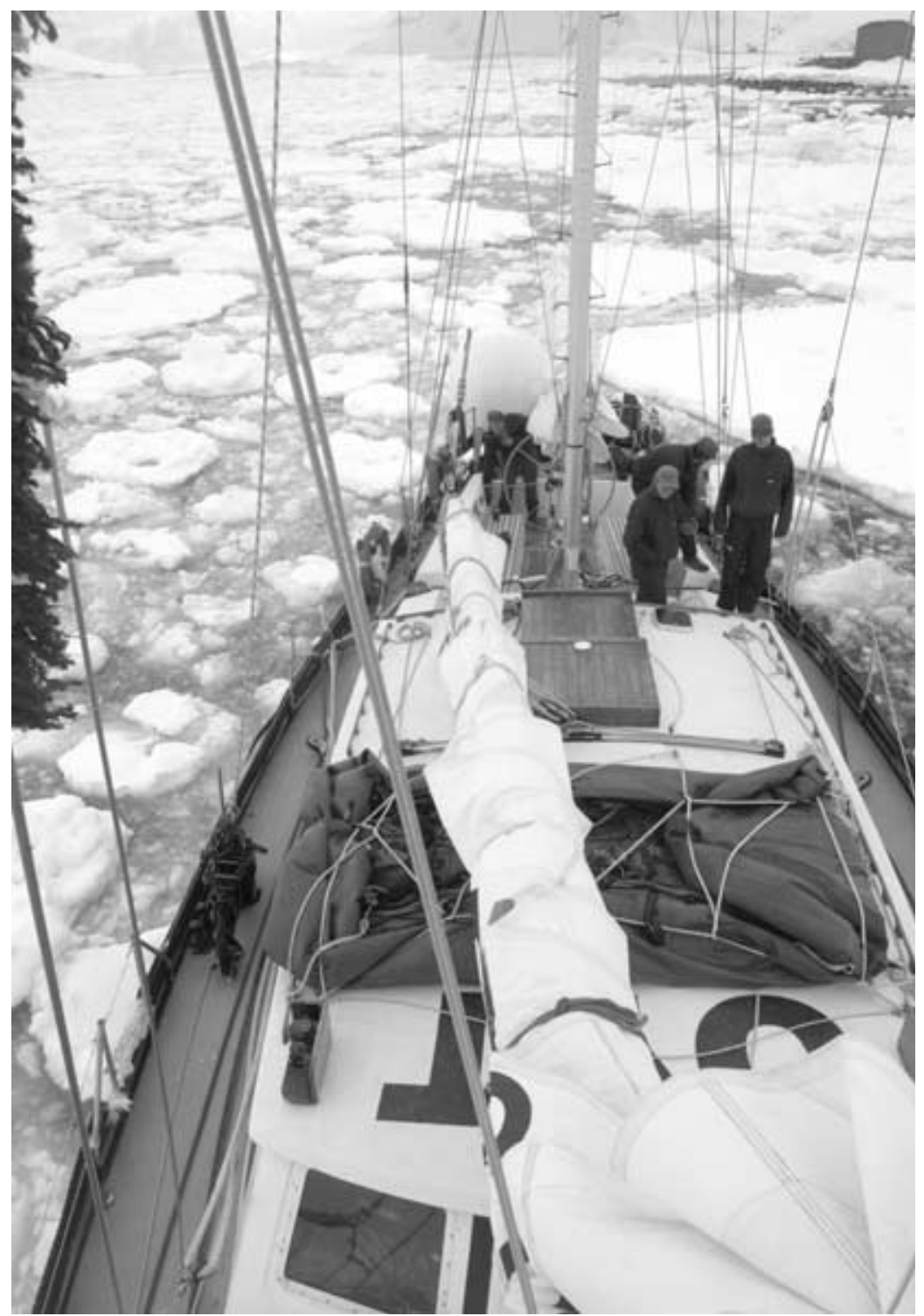

Fig 7. Stuck in ice. size of a laptop computer. Its battery will take 500 pictures. If I can get hold of one, I'll take it next time ${ }^{1}$. Also, the first time one needs to apply a Bennett's cast in anger is not the ideal time for an inexperienced practitioner to be experimenting with Scotchcast. I managed a reasonable job after 4 rolls. With hindsight it would have been easier to visit a plaster room for an hour first.

\section{Minor ailments}

It is essential not to underestimate the impact that a relatively minor injury can have on a man pulling a sled for 23 hours in sub zero conditions while dry and hungry. I thought I had enough Compeed for blisters. I did not. Molnicke's Mepilex works very well for larger ones but I ran out of that too. Dehydrated rations inevitably result in piles, so it is important to take at least twice as much anusol as one can possibly imagine needing.

\section{Communications}

Telemedicine was a vital asset on several occasions. Our satellite equipment allowed full telemedicine support from Haslar. It is vital to remember to find out what it can do, and how to use it from the Telemed Unit before you go. I would also advise taking contact details for a couple of friendly specialists with you. A satellite phone call is like manna from heaven when you are 1100 miles from a hospital, and unsure what to do.

\section{Conclusion}

Finally, I would advise anyone thinking about going on an expedition to stop thinking about it. Go. Practicing medicine and being part of a team in a place like the Antarctic is a wondrous thing, which you will remember with pleasure for the rest of your life. If the opportunity comes along, take it.

${ }^{1}$ NATO stock number 6635-99-214-1279. 